SIMONS, D. J., DAY, E., GOODELL, H., and WOLFF, H. G. (1943), Research Publ. A. Nerv. and Ment. Dis., 23, 228. SINKLER, W. (1887-88), Maryland fournal, 18, I.

SLATER, J. K. (1948), Edinb. Med. F., 55, 173.

SMITH, C. B. (1946), Canad. M. A. Ұ., 54, 589.

SOLTZ, S. E., BRICKNER, R. M., RIL̈EY, H. A., and SALMON, L. A. (1935), Bull. Neurol. Inst. N. York, 4, 432 SPITZER, A. (1901), 'Ueber Migräne,' Jena.

SPUEHLER, O. (1946), Schweiz. Med. Wschr. 76, 1259.

VON STORCH, T. J. C. (1937), Nervenarzt, 10, 469 .

VON STORCH, T. J. C. (1937), New Eng. Ұ. Med., $217,247$.

VON STORCH, T. J. C. (1938), F. Am. Med. Ass., III, 293.

VON STORCH, T. J. C. (1941), Med. Clin. N. Am., 25, 1317.

VON STORCH, T. J. C. (1947), Amer. Practit., I, 631.

SUTHERLAND, A. M., and WOLLFF, H. G. (1940), Arsh. Neurol. and Psychiat., 44, 929.

THOMAS, W. A., and BUTLER, S. (1946), Am. F. Med., r, 39.

THOMAS, W. A., and BUTLER, S. (1946), Bull. N. York Acad. Med., 22, 125 .

TILLGREN, N. (1947), Nord. Med., 33, 502.

TILLGREN, N. (1947), Nord. Med., 34, 937.

TILLGREN, N. (1947), Acta Med. Scand. (Suppl.), 196, 222.

TILLIM, S. J. (1944), Ann. Int. Med., 20, 597.
TODD, R. B. (1854), 'Clinical Lectures on Paralysis, Diseases of the Brain and Other Affections of the Nervous System,' London, p. $28 \mathrm{r}$.

TORDA, C., and WOLFF, H. G. (1945), Arch. Neurol. and

TROWBRIDEGE, 53 . 329 . S., VON STORCH, T.J. C., and MOORE, M. (r942), New Eng. F. Med., 227, 699.

UNGER, L. (1940), F. Allergy, $12,197$.

VALLERY-RADOT, P and BLAMOUTIER, P. (1927), Bull. et Mem. Soc. Med. Hop. Paris, 5I, 925.

VILLEY, G., and BUVAT, J. F. (1937), Paris Med., 103, 189.

VON WASSERMAN, A., NEISSER, A., and BRUCK, C. (1906) Dtssh. Med. Wchschr., 32, 745.

WEISMANN, S. (r924), ' Des Migraines,' Paris.

WHITEHEAD, R. W., and MCNIEL, E. E. (1935), Am. Ұ. Psychiat., 91, I275.

WHITEHORN, J. C.'(1944), Arch. Neurol. and Psychiat., 52, 197. WILSON, D. C. (1925), Clifton M. Bull., II, 7I.

WOLFF, A. A., and UNGER, L. (1044), Ann. Int. Med., 20, 828.

WOLFF, H. G. (1940), 'Modern Medical Therapy in General Practice, Baltimore.

WOLFF, H.' G. (I948), 'Headache and other Head Pain,' New York.

WOLFF, H. G., HARDY, J. D., and GOODELL, H. (I94I), $\mathscr{f}$. Clin. Invest., 20, 63.

\title{
INFECTIONS OF THE FEET IN DIABETES
}

\section{With Special Reference to Those Due to Gas-Forming Organisms}

\author{
By E. C. B. ButLER, F.R.C.S. \\ The London Hospital
}

It is a common error to regard all infections of the feet occurring in diabetic patients as cases of incipient gangrene. Most of these patients can be safely treated at home or in the out-patient department. Only a minority need admission to hospital, and of these only a small proportion have true necrosis or require a major amputation. The incidence of severe infection has been much reduced since the introduction of penicillin.

Patients who require in-patient treatment may for convenience be divided into two groups, although the dividing line between the two is often difficult to determine.

Group I consists of those patients who have signs and symptoms of senile obliterative arterial disease. The diabetic cases differ only in having infection as a constant feature.

Group 2 consists of cases of diabetes complicated by infection of the feet, the circulation being good, the popliteal pulse being readily felt and oscillometer tests showing good pulsation below the knee.

\section{Group I}

Following mild trauma an infection starts on one or more toes and similar lesions may arise on the heel or elsewhere on the foot. Under favourable circumstances and treatment the infection will resolve but in other instances it may spread or go on to necrosis, which in turn may remain localized or involve the remainder of the foot.

When spread of the infection occurs there is little local reaction; formation of pus is unusual and there is no definite line of demarcation between diseased and healthy tissue. On examination, these patients are likely to show signs of thrombosis in the femoral or popliteal vessels. Popliteal pulsation is absent, oscillometer readings show minimal or absent records below the knee and the limb rapidly becomes blanched when elevated. Radiography may reveal widespread medial calcification of the main vessels.

\section{Treatment}

The patient is best treated as an in-patient. A swab from the infected area is sent to the laboratory so that the invading organisms can be identified and their sensitivity established.

Staphylococcus aureus and haemolytic and nonhaemolytic streptococci are commonly found; but gram-negative bacilli may also occur. Not infrequently various types of anaerobic organisms are present and these may cause serious spreading infections. Some of these organisms are penicillin resistant and it is a wise precaution to learn without delay what drug or combination of drugs is 
likely to prove effective should the infection become severe. The affected limb should be kept at room temperature and rested on a soft pillow; care must be taken of both heels since pressure necrosis is very liable to occur. Intermittent venous occlusion has not in our experience been helpful in these cases, but active physiotherapy aids the circulation and helps to prevent the patient developing further thrombosis. Local treatment should consist in removing any slough which is present or in cutting away any obviously necrotic phalanx. It is a mistake to leave tenacious adherent sloughs on the ends of toes; underneath these sloughs the infection persists and may spread. Formal amputation of toes through the metatarso phalangeal joints is contraindicated since it is likely to lead to a rapid spread of the infection, or to necrosis.

Local application of penicillin and sulphonamide powder is not of great value in the presence of necrotic tissue; the powder tends to cake and penetration is limited. Until the slough has separated hypertonic saline dressings or eusol compresses are often useful. When there is no slough the part should be kept dry by means of a spirit dressing.

A course of systemic penicillin may be valuable in preventing cellulitis, but it is not necessary to continue penicillin therapy indefinitely in the absence of an acute infection or while awaiting the separation of necrotic areas.

In most cases the infection will subside and the necrosis, if present, will remain limited to one toe. If the patient is fortunate the dead area will separate spontaneously with, perhaps, slight judicious aid.

The indications for amputation in this group are similar to those for patients with uncomplicated senile gangrene, namely spreading necrosis and intolerable pain. Fulminating infection is sometimes an additional indication and is considered later.

The average age of patients in this group was 64, the oldest being 78 and the youngest 51 . In

\section{TABLE}

Results in 18 Cases with Absent Popliteal Pulsation

\begin{tabular}{|c|c|c|c|c|}
\hline \multirow{3}{*}{$\begin{array}{l}\text { Above knee amputation } \\
\text { Below knee amputation } \\
\text { Local removal of slough } \\
\text { No surgery }\end{array}$} & \multirow{3}{*}{$\begin{array}{l}\ddot{\cdots} \\
\ddot{*} \\
\cdots\end{array}$} & & Alive & Dead \\
\hline & & $\begin{array}{l}6 \\
0 \\
6 \\
6\end{array}$ & $\begin{array}{l}4 \\
0 \\
6 \\
5\end{array}$ & $\begin{array}{l}2 * \\
0 \\
0 \\
\text { I† }\end{array}$ \\
\hline & & 18 & I 5 & 3 \\
\hline
\end{tabular}

* One heart failure, one gas infection.

+ Heart failure.
TABLe 2

Results in 22 Cases with Poor Circulation but in Whom no Note was made of the Popliteal Pulsation

\begin{tabular}{|c|c|c|c|c|c|}
\hline & & & & Alive & Dead \\
\hline $\begin{array}{l}\text { Above knee an } \\
\text { Below knee an }\end{array}$ & $\begin{array}{l}\text { ation } \\
\text { ation }\end{array}$ & $\begin{array}{l}\cdots \\
\cdots\end{array}$ & $\begin{array}{l}\mathbf{I} \\
\mathbf{0}\end{array}$ & $\begin{array}{l}\mathbf{I} \\
0\end{array}$ & $\begin{array}{l}0 \\
0\end{array}$ \\
\hline Local surgery & $\cdots$ & . & 9 & 7 & $2 *$ \\
\hline No surgery & $\cdots$ & $\ldots$ & 12 & 12 & 0 \\
\hline & & & 22 & 20 & 2 \\
\hline
\end{tabular}

* Both gas infections.

a similar series of arterio-sclerotic patients with gangrene the average age was 63 .

\section{Group 2. Cases with Popliteal Pulse Present}

In this group, since the blood supply is good, infection rarely leads to gangrene except in those cases where gas infection supervenes. Abscess formation is common and infection readily tracks up the layers of the foot causing sloughing of the tendons and fasciae. Osteomyelitis with sequestration of the affected toes frequently occurs.

A number of these patients also have diabetic neuritis; this manifests itself by the presence of perforating ulcers, commonly at the ball of the bige toe. An X-ray invariably shows underlying infective arthritis with osteomyelitis of the adjacent bones.

In one of our cases the neuritis was so marked that the patient developed a fracture of one of her metatarsals without complaining of pain or discomfort. The healed fracture was discovered when the foot was X-rayed for a perforating ulcer (Fig. I). A perforating ulcer may remain quiescent for a long time save for a persistent painless discharge. Suddenly for no apparent reason infection lights up and may prove the starting point of a rapidly spreading cellulitis. We have also found that a small number of this group suffer from increasing blindness due to diabetic retinopathy. The double handicap of infected feet and impairment of vision is a hard burden. Every effort must be made to avoid a major amputation on these patients as it is difficult for them to use crutches. In our experience both retinopathy and diabetic neuritis have occurred only in Group 2 cases, although it is possible that both complications may arise in patients with arterio-sclerosis.

\section{Treatment}

On admission to hospital a swab is taken from the infected area. In this group chemotherapy is likely to be more valuable than in Group I, and an accurate bacteriological diagnosis is essential. Systemic penicillin may often be combined with a course of sulphonamide and it is probable that in 
the future aureomycin will be a most valuable addition in the more severe types of anaerobic infection. McKitterick and Root (1936) were among the first to emphasize that if the blood supply of a diabetic patient's foot is good enough to form pus then it is good enough to tolerate.local surgery.' This important statement should be remember $r$ d.

Abscesses should be drained freely in exactly the same manner as in infections of the hand. The incisions must be adequate. In the foot the webs between the toes commonly require drainage and thence the incisions may be prolonged on to the dorsum or sides of the foot. Drainage via the sole should be avoided where possible. Necrotic tendons and fascia must be completely excised if the wound is to heal; this may be done at a second operation if the field is obscured by pus. In certain cases, once the acute phase is over, formal amputation of the diseased toes or metatarsals can safely be performed (Fig. 2). These wounds may be sewn up confidently provided that all the dead tissue has been removed. Systemic penicillin should be continued until the wounds have healed.

When a toe has been amputated it is wise to excise at the same time the head of the underlying metatarsal. If this is omitted the cartilage may slough since a part of its blood supply derives from the excised joint (Figs. 3 and 4). In two cases we have carried out amputation of the big toe and three-quarters of the first metatarsal for perforating ulcers below the first metatarso-phalangeal joints with osteomyelitis of the adjacent bones. They have healed well. Walking has been satisfactory with special surgical shoes. In cases where the foot has become useless amputation at a higher level must be considered.

Syme's amputation has lately fallen into disrepute in this country but we have found it a satisfactory procedure in certain of these patients. The late Dr. Leyton who was for many years in charge of the diabetic clinic at the London Hospital was always very insistent, in the light of his experience, that his patients had as conservative an amputation as possible. We have followed his teaching in this matter. In cases of doubt it is safe to perform a below-knee amputation at the site of election provided the oscillometer shows adequate pulsation in this region.

The average age of Group 2 patients was 54 ; the eldest was 67 and the youngest 32 .

\section{Gas Cellulitis and Gangrene}

This condition may be defined as infection of the lower limbs in diabetic patients by gas-forming organisms other than the clostridiae.
TABLE 3

Results in 25 Cases with Palpable Popliteal Pulse

\begin{tabular}{|c|c|c|c|c|}
\hline \multirow{6}{*}{$\begin{array}{l}\text { Above knee amputation } \\
\text { Below knee amputation } \\
\text { Syme's amputation } \\
\text { Local surgery .. } \\
\text { Removal of metatarsal } \\
\text { No surgery }\end{array}$} & \multirow{6}{*}{ 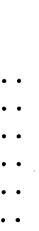 } & & Alive & Dead \\
\hline & & $\mathbf{I}$ & 0 & $\mathbf{I}$ \\
\hline & & 4 & 2 & 2 \\
\hline & & 3 & 3 & 0 \\
\hline & & 8 & $\begin{array}{l}8 \\
2\end{array}$ & 0 \\
\hline & & 6 & 6 & 0 \\
\hline & & 25 & $2 \mathrm{I}$ & 4 \\
\hline
\end{tabular}

Three of the deaths were due to gas infection and one to cerebral haemorrhage.

\section{Bacteriology}

A variety of organisms has been encountered. Aerobic cultures have shown the common grampositive cocci, but bacilli of the colon group are also found in large numbers. Faecal streptococci occurred in one case. Anaerobic cultures are usually disappointing. The most probable pathogens responsible are anaerobic streptococci, faecal streptococci and fusiform bacilli. Clostridial infection was not seen in all cases examined bacteriologically.

\section{Symptoms}

These infections usually start from a previous focus of infection such as a perforating ulcee. occasionally, however, they may arise de nova? The patients rapidly become very ill and in fulminating cases death may occur in a few days. On admission there is high fever and a rapid pulse. The urine is loaded with sugar and contains acetone. The glycosuria tends to persist despite massive doses of insulin. At first the cellulitis remains localized but soon spreads up the foot into the leg. Gas is readily detected in the subcutaneous tissues and can be demonstrated radiologically. If the disease is unchecked true gas gangrene develops, the muscles becoming necrotic and putrid with bubbles of gas between the fibres.

In a short time the lower limb may become a mass of stinking necrotic tissue. Death usually results from a combination of severe diabetes, toxaemia and terminal bronchopneumonia. Bacteraemia does not seem to occur; none of our cases developed a positive blood culture.

These severe infections may occur in either of $N$ the two groups we have described; indeed the $N$ most severe cases have been in patients whose $\mathbb{W}_{\mathrm{W}}$ blood supply has been adequate. The following case histories illustrate the aetiology of such infections and bring out the problems involved.

\section{Case I}

Woman aged 55. Several months increasing 


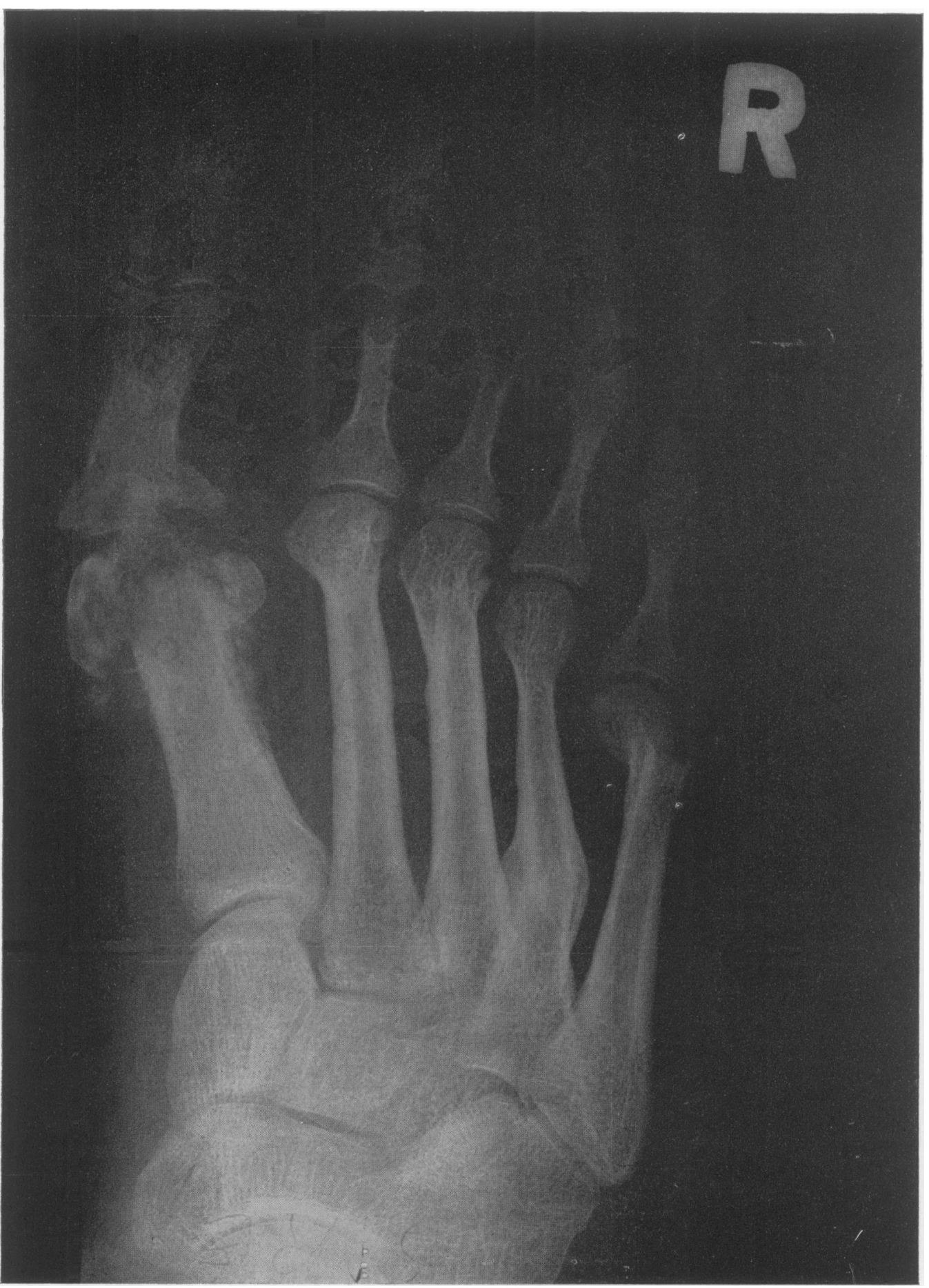

FIG. 1.-The typical appearance of the bones and joint underlying a perforating ulcer of the big toe. Healed fractures of the fourth and fifth metatarsals also present.

(Reproduced by kind permission of 'The Iondon Hospital Gazette') 


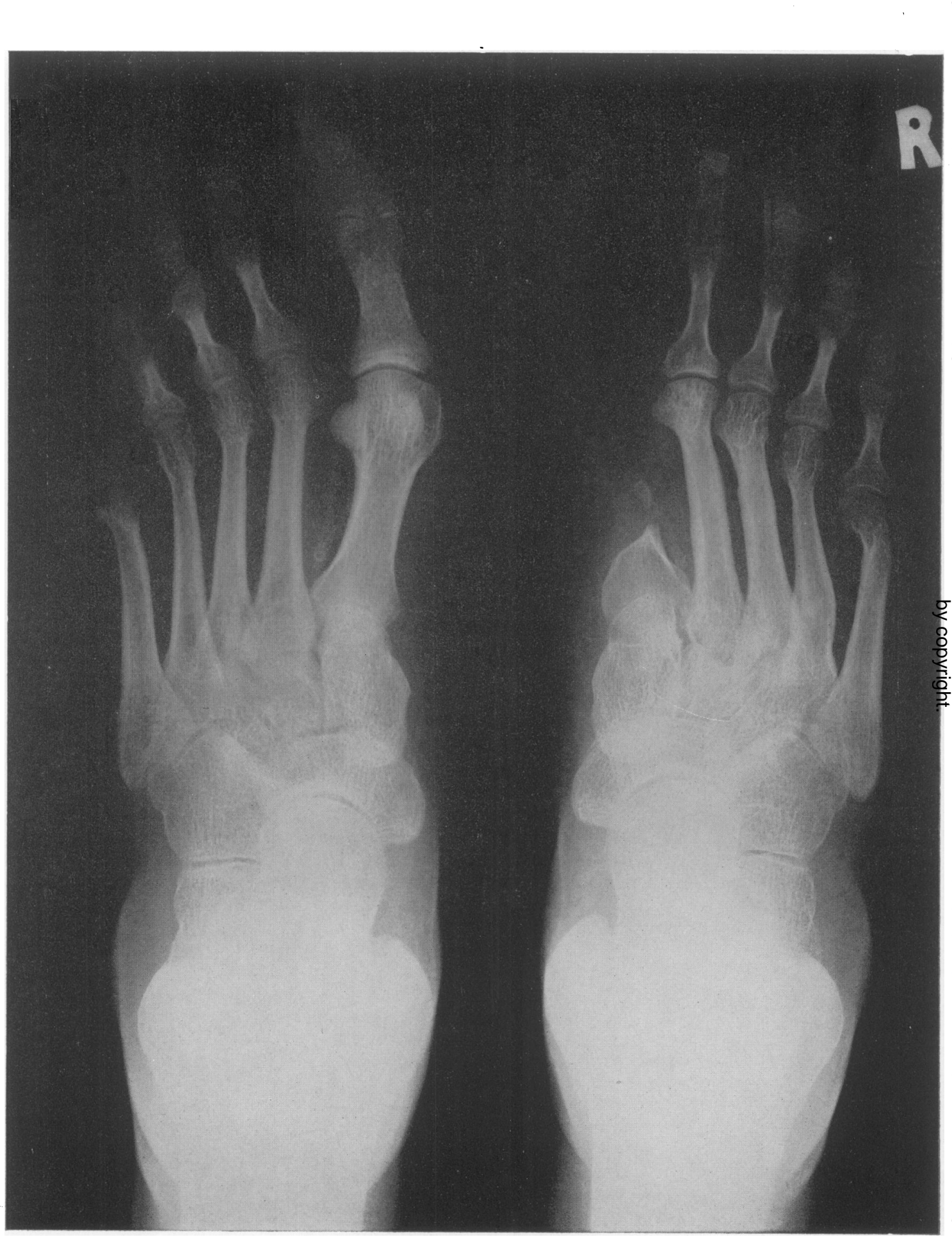

Fig. 2. - An X-ray of the same foot after amputation of three-quarters of the metatarsal, together with the big toe. The wounds healed by first intention and the patient walked well with a special shoe. 


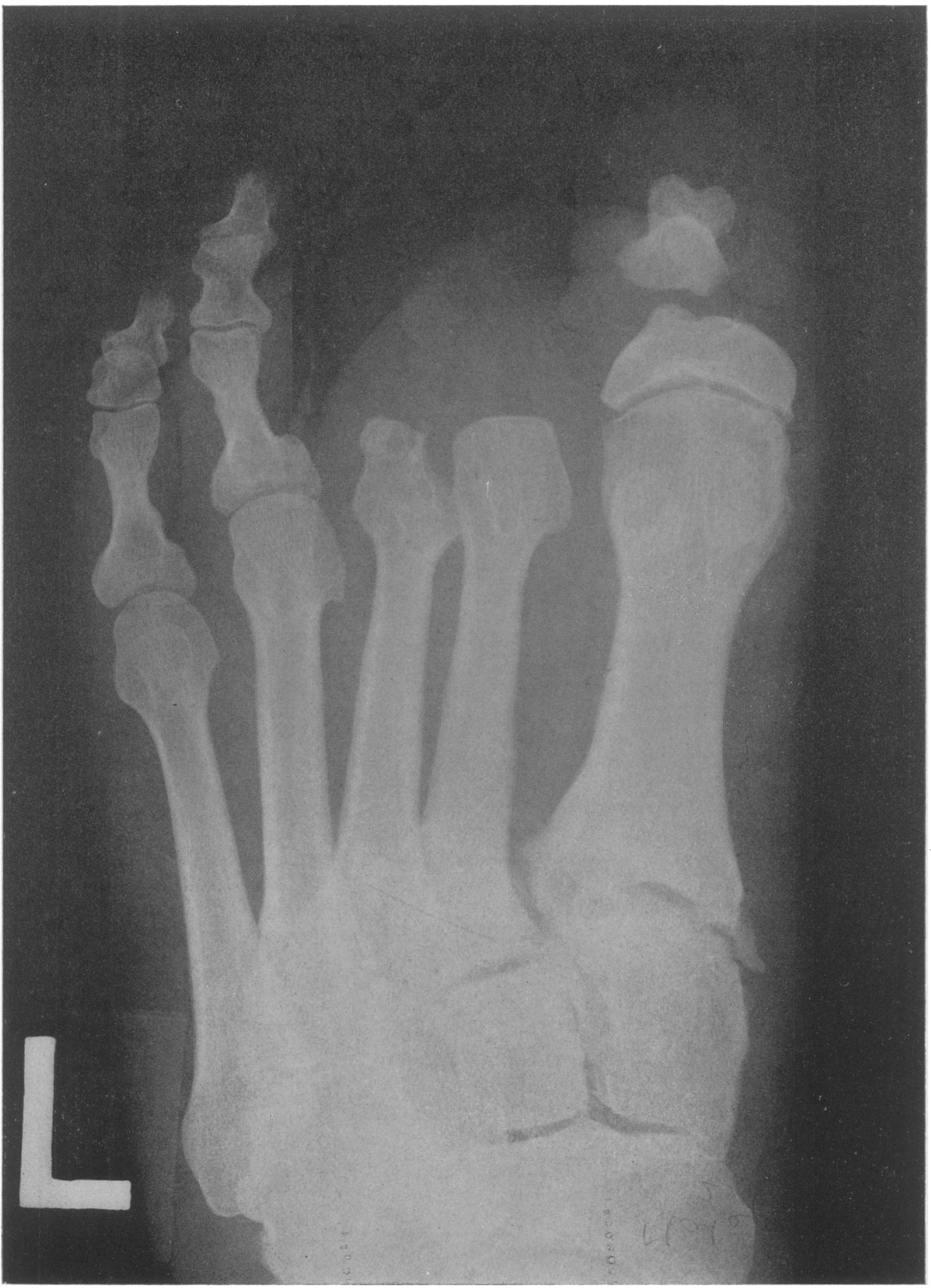

Fig. 3. - This picture was taken immediately after amputation of the second toe through the metatarsophalangeal joint. The third and part of the first toes had been removed previously for infection.

(Reproduced by kind permission of 'The London Hospital Gazette') 
thirst. Three weeks painful toe. No previous diagnosis of diabetes.

14.12.38. Patient admitted to hospital, an ill dehydrated woman with sugar and acetone in her urine. The popliteal pulse was felt; there was an area of infected necrosis of her fifth right toe. The diabetes was controlled with insulin. In spite of intermittent venous occlusion and a course of sulphanilamide the infection spread and the foot became gangrenous, gas being present.

26.12.38. Amputation of leg below knee with suture of the flaps. Gas gangrene rapidly appeared in the stump and she died three days later.

The post-mortem examination showed gas gangrene with gas in the liver.

Comment. Two mistakes were made in the treatment of this patient. Amputation was performed far too near the site of infection and the flaps were sutured instead of being left open.

\section{Case 2}

Man aged 59. Two weeks painful heel following slight injury. No previous diagnosis of diabetes.

14.1 I.43. Admitted to hospital with diffuse cellulitis of the foot. The popliteal artery could not be felt. The urine was loaded with sugar and acetone.

15.11.43. Gas infection was obvious; incisions were made in the foot and leg, gas and pus were liberated. A course of sulphonamide was commenced. Culture showed a haemolytic streptococcus as well as staphylocossus aureus.

16.11.43. The man died.

Post-mortem report: Gangrene of leg; pancreatic calculi.

Comment. It is difficult to see what further could have been done. An emergency amputation might have been carried out but would probably have proved fatal.

\section{Case 3}

Female aged 68. Known to be diabetic. Ten days malaise with pain in one foot.

20.5.47. Admitted to hospital; temperature $100^{\circ}$, pulse 100. Urine full of sugar. There was diffuse cellulitis of one foot but the popliteal artery could be felt. Cultures from the foot: Staphylococcus aureus. Anaerobic cultures: No growth.

Treatment. Penicillin; 200,000 units was given four hourly.

25.5.47. Two large incisions made in foot and leg. Gas and pus liberated. Her condition improved considerably and a line of demarcation appeared below the knee.

16.6.47. Amputation of the leg below the knee, flaps not sutured. For ten days she remained well then her diabetes became uncontrolled, and although the leg infection did not recur she died of bronchopneumonia.

No post-mortem examination.

Comment. The gas infection was checked by penicillin and surgery; unfortunately the diabetes relapsed after removal of her gangrenous leg.

\section{Case 4}

Man aged 57. Since 1947 had been treated in hospital for severe diabetes with infections of the feet; these had cleared up with chemotherapy and drainage. For two weeks he had had a painful toe.

30.8.48. On admission, an ill man with severe diabetes, there was gross swelling of one foot of which one toe was gangrenous. The diabetes was not controlled with insulin. The popliteal pulse was palpable.

Treatment. Penicillin, one million units daily, in spite of which the cellulitis spread and gas became evident. Amputation was refused.

18.9.48. Left leg drained by two large incisions; gas gangrene of muscles present. Culture: Staphylococcus aureus and streptococcus faecalis. B. coli also present. A blood transfusion was given. After drainage his condition improved for a time but later relapsed.

21.9.48. Amputation performed through the thigh; flaps not sutured. Patient collapsed an died two hours after operation.

Post-mortem report: Toxaemia, diabetes.

Comment. The infection was partially checked by treatment; the optimum time for amputation would have been when his condition improved after drainage. These patients are very ill and major operations are always hazardous.

\section{Case 5}

Woman aged 45. Known diabetic for many years. Controlled by insulin. Five years a perforating ulcer under one big toe. One week increasing pain and swelling of big toe.

On admission, 1948, ill woman. Temperature $102^{\circ}$, pulse 100 . Severe glycosuria. One foot was swollen with a perforating ulcer of the big toe. Her popliteal artery was palpable. X-ray showed calcification of the vessels of the foot and leg and gas in the foot.

Treatment. Penicillin, 250,000 units threehourly for four days. At the end of which time no further spread had occurred. A large abscess was drained on the dorsum of her foot. Culture: Staphylococcus aureus and anaerobic streptococci. Three weeks later a sequestrum was removed from her toe. She has remained well since.

Comment. This patient's infection fortunately responded to penicillin; without this drug she might well have lost her leg, if not her life. 


\section{Case 6}

Man aged 54. Two years known diabetic. Two months infected toe; two weeks worse.

On admission, 1949, ill man with glycosuria and cellulitis of one foot. His popliteal artery was palpable. Culture from the foot: Non-haemolytic streptococcus.

Treatment. One million units of penicillin daily. Despite this therapy his infection spread and he suffered intense pain. The odour of the foot became very offensive although no actual gas was demonstrated. A below-knee amputation was carried out; secondary suture of the flaps being carried out on the fifth day. The wound healed without suppuration.

Comment. This case has been included as it shows the ideal treatment to be adopted in such cases whenever practicable. If the circulation below the knee had been poor, then a thigh amputation would have taken the place of a belowknee one.

From these case records it is obvious that we are dealing with a very serious and often fatal infection. In many ways they resemble those cases of gas cellulitis seen after war wounds, although the bacteriology is not identical, but they are more serious because they occur in old and debilitated patients. Moreover, a higher percentage terminate in true gas gangrene of muscle than did those following war injuries.

In our view the principles of treatment of such cases should be:

I. The infection must, if possible, be controlled by large doses of penicillin. If there is no rapid response to this drug another antibiotic must be added, aureomycin being the most promising at the present time.

2. Immediate surgical intervention is usually unwise, but as soon as pus has formed free drainage must be carried out.

3. Emergency amputations before the infection has been controlled are dangerous and may be fatal.

4. Should amputation be required the flaps must never be sutured, they should be loosely tied together over a pack; secondary suture can be done on or after the fifth day in favourable circumstances.

5. Blood transfusions are valuable to counteract the progressive anaemia which is usually present.
There is no doubt that the cases treated with ڤ̊ penicillin showed greatly improved results. $\frac{3}{8}$ Although twb of these four cases died, in all the $\stackrel{\varnothing}{\varnothing}$ infection was checked at least temporarily by a $\stackrel{.}{.}$ combination of chemotherapy and surgery. It $\overrightarrow{\vec{S}}$ was impossible to control the glycosuria in these patients until the infection had been overcome; the demand for insulin then fell dramatically.

\section{TABLE 4}

Results of Nine Cases of Gas Infection

\begin{tabular}{|c|c|c|c|c|}
\hline Sex & $\begin{array}{c}\text { Pop- } \\
\text { liteal } \\
\text { Artery }\end{array}$ & Chemotherapy & $\underset{\text { Treatment }}{\text { Surgical }}$ & Result \\
\hline Male & $\begin{array}{l}\text { Not } \\
\text { felt }\end{array}$ & Sulphonamide & Amputation & Died \\
\hline Female & Felt & Sulphonamide & Amputation & Died \\
\hline Male & Felt & Penicillin & $\begin{array}{l}\text { Amputation } \\
\text { thigh }\end{array}$ & Died \\
\hline Male & $\begin{array}{l}\text { Not } \\
\text { felt }\end{array}$ & Sulphonamide & Drained & Died \\
\hline Female & Felt & Sulphonamide & $\begin{array}{l}\text { Amputation } \\
\text { thigh }\end{array}$ & Lived \\
\hline Female & $\begin{array}{l}\text { Not } \\
\text { felt }\end{array}$ & Sulphonamide & Drained & Died \\
\hline Female & Felt & Penicillin & Amputation & Diede \\
\hline Male & Felt & Penicillin & Amputation & Liveg̊ \\
\hline Female & Felt & Penicillin & Drained & Live高 \\
\hline
\end{tabular}

\section{Conclusions}

I. This paper is based on a series of 62 patients treated as in-patients at the London Hospital. There were nine deaths, six from gas infection, two from cardiac failure and one from cerebral haemorrhage.

2. Diabetic patients with infections of the feet can be divided into two groups; those with arteriosclerosis and those in whom the vascular supply below the knee is still good.

3. The treatment of the first group is that of arterio-sclerosis in general, but infection is always an added complication.

4. The treatment of the second group is based on the usual surgical principles of the treatment of sepsis. Gangrene is rare and local measures are often successful.

5. The dangers of gas cellulitis and gangrene in both groups have been discussed. Nine cases are reported with six deaths. 